The chapters on excretion, osmoregulation, biochemical affinities and respiratory physiology give useful surveys, but others are not so up to date. Important work has been carried out on feeding, digestion, chemical composition, toxins, sensory physiology, the excitable tissues, the water-vascular system and on spawning and neurosecretion which is not treated by the text. Of the references cited there, less than 5 per cent concern papers published after 1966, the date of the previous review of the subject. The author has provided an addendum of about 250 references, mostly to work carried out between 1966 and 1970, but these are not dealt with by the text so they merely direct the reader to possible sources of information.

Echinoderms constitute a singular group of animals, and many aspects of their biology are unique. Consequently the book would have been improved by the inclusion of an adequate introductory chapter. Readers not familiar with the phylum may have some difficulty with unexplained terminology, and little guidance is given on the organization and classification of the group. Although the author stresses that the unusual symmetry and the absence of a head have influenced the development of certain physiological systems, he might have emphasized other significant features that echinoderms display. These include the exclusively marine habit, the large coelom and the unique skeleton.

The usefulness of the book could have been increased if it had been planned differently. As it is, some information that would be of use earlier in the text is withheld until later and the headings and cross references do not always lead one to the expected information.

While this book will be valuable for some aspects of undergraduate work, it will be of limited assistance to the researcher because it is out of date in several respects.

Andrew C. Campbell

\section{Viruses of Man}

Strains of Human Viruses. Edited by M. Majer and S. A. Plotkin. Pp. $x+271$. (S. Karger: Basel and London, 1972.) This book fulfils a long standing need in virology. Edited by $M$. Majer and S. A. Plotkin, with individual chapters contributed by different workers, it is a catalogue of the strains of human viruses which are either official prototype strains or which have been widely used by workers in the fields involved. Strains used for vaccines and those with genetic markers are also listed. In each case, the source of the original isolate and the laboratory where the first isolation was made are given together with the passage history and a summary of the characteristic features of the strain. No book, of course, is perfect, and it is a real pity that in most instances there is no mention of the laboratories from which the viruses may be obtained. References to the literature on each strain are given which the editors suggest should be consulted for this information, but this is much less useful than a list of laboratories which stock the strain concerned. The editors also make apologies to "the scientist whose pet strain has been omitted" and there are certainly a few surprising omissions some of which will no doubt be corrected in a second edition. A more serious criticism is that in the chapter on herpes simplex virus it is not always stated if the strain is type 1 or type 2 . In cases in which serological typing has not been done this should have been stated-although it is doubtful if such a strain merits inclusion at all. These criticisms, however, are minor and do not seriously detract from an exceptionally useful book. It will undoubtedly become an indispensable reference book in all virus laboratories. Morag C. Timbury

\section{Plant Hormones}

Plant Hormone Research in India. By S. M. Sircar. Pp. vi+264. (Indian Council of Agricultural Research: India, New Delhi, 1972.) Rs. 12.50.

THIs is a comprehensive volume, divided into three parts. The first provides a general account of plant hormones including historical aspects, terminology, chemistry, methods of application and mode of action. The second part is concerned mainly with the practical uses of hormones and, in addition to well known applications such as rooting, fruit setting and weed control, the effects of hormones on plant metabolism and their role in promoting growth of plant tissues and organs in sterile culture media are discussed. An account is also given of hormone inhibitors and growth retardants. In the third part of the book the author considers the potentials of growth hormone research. There is a chapter dealing with hormones in tropical plants in which particular attention is given to the results of Indian workers. The final chapter considers the importance of hormones in bud, stem, and fruit growth, abscission of leaves and fruit, and senescence.

Apart from the special attention given to Indian plants there is nothing very novel about this book. However, it is quite well produced, with useful photographs, diagrams and an extensive bibliography and it has brought together most of the important findings of hormone research. Because of its special emphasis on local plants and crops it will be especially useful to botanical and agricultural students in India.

R. L. WaIN

\section{Pictures of Rocks}

The Minor Structures of Deformed Rocks: a Photographic Atlas. By L. E. Weiss. Pp. viit 431 . (203 plates.) (Springer: Berlin and New York, 1972.) 94 DM; \$29.80.

THIs unusual book, which has been described as an atlas, contains more than 200 full or half-page plates with brief paragraphs, stating the types of structures, rocks and localities illustrated; a brief six-page introduction is followed by a further twelve pages, entitled "Introduction to Plates", two pages of references and a short subject index completes the text.

The author states that the main aim of the book is merely to illustrate the common minor structures resulting from rock deformation. The interpretation of such structures is left to other texts. For my part, I cannot agree with the author when he asserts that most field geologists are not and should not be concerned with the mechanical problems of rock flow. I believe that most people only "see" those things they understand, or think they understand. To this end I would have liked to see more interpretation in this book.

This apart, the book stands or falls on the coverage of material and the standard of photographic reproduction. The work contains about fifty plates illustrating planar features, more than seventy on folds and almost eighty further plates dealing with lineations, boudinage, veins and "complex" structures. The author freely admits that these structures represent his main interests and he has made no effort to include coverage of faults and joints, an omission which I find regrettable. The quality of the photographic content. which is due wholly to the author, and of the reproduction, ranges from acceptable to excellent, with a preponderance of the latter.

This work will doubtless be used by students as a "photographic" dictionary - a form of Duden-and, in addition, I am sure that teachers of structural geology around the world will contravene the laws of copyright and reproduce many of the plates presented, to augment their own teaching material. Neville J. Price 